\title{
THE EFFECT OF ENVIRONMENT ON HERITABILITY AND PREDICTED SELECTION RESPONSE IN MEDICAGO SATIVA
}

\author{
H. DADAY,* F. E. BINET, $†$ A. GRASSIA $\ddagger$ and 1. W. PEAK*
}

Received 16.xi.72

\begin{abstract}
SUMmary
This investigation concerns the effect of environments on mean plant growth, heritability, and predicted selection-response of metric characters in $M$. sativa at three locations.

The three natural environment " treatments" (high, medium and low) were determined by the differing degrees of daylight, temperature and moisture available. It is noted that this climatic variation took place within the geographical locations as well.

Mean plant height was significantly lower in the medium and low environments than in the high environment. The heritability estimates $\left(\hat{h}_{n}^{2}\right)$ of plant growth varied between 0.16 and 0.46 under high and medium treatments at the three locations, but it was reduced to zero by the low treatment.

The family $\times$ locality interaction varied between the particular climatic environments.

The expected responses to direct selection were highest in the medium treatment, second highest in the high and lowest in low.

All the predicted responses to direct selection were higher than those to any indirect selection.

Nonetheless indirect selection was found to be advantageous if a particular locality was exposed to frequent environmental stress, provided only that the family $\times$ locality interaction was not excessive.

It is concluded from these investigations that unfavourable environmental conditions may severely limit response to selection, while unusually favourable ones may do so to a moderate extent. Therefore judiciously applied indirect selection may yield more genetic progress than direct one in $M$. sativa popula tions under certain extreme conditions.
\end{abstract}

\section{Introduction}

THE effect of an environmental change on selection-response of metric characters is a controversially treated problem in quantitative populationgenetics. Hammond (1947) stated that an unfavourable environmental condition can be a limiting factor in the response to selection of (economically useful) animals; moreover he claimed that if this limiting factor is removed (by replacing it with conditions favourable for the development of the character in question), then selection for alleles conditioning to a higher level of production becomes more effective even under less favourable conditions.

Falconer (1952) and Falconer and Latyszewski (1952) studied the effect of "high" and "low" planes of nutrition on the improvement in body weight achieved by selection in mice. Heritability, as estimated by selection response, was higher (although not significantly) on the "low plane" of nutrition. In apparent contrast to Hammond (loc. cit.) they concluded that: ". . . improvement attained by selection under ' good' conditions was not

* Division of Plant Industry, CSIRO, Canberra, Australia.

+ Divisian of Animal Genetics, CSIRO, Epping, Australia.

† Division of Mathematical Statistics, CSIRO, Canberra, Australia. 
realized when the selected strain was transferred to 'bad' conditions: instead of being better than the strain selected under bad conditions it was worse, and showed no evidence of any advance beyond the initial level ".

The problem of choice between these two contrasting views when applied to an outbreeding plant species like, e.g. Medicago sativa L., has been examined in "favourable" and "unfavourable" environments (both natural). As much of the distribution of this species extends to areas of varying unfavourable climatic conditions, consideration of environmental effects on the selection with respect to metric characters and on the cultivation of the selected strains is an essential prerequisite of the applicability of the results of controlled experiments in natural field conditions.

The aims of the present investigation are, firstly, to examine the effect of various environments and of climatic fluctuations on the observable heritability of growth characters; secondly, to determine the magnitude of genetic correlations between analogous characters measured in different environments; finally, to estimate the expected (direct and concomitant) responses to selection.

\section{Material and Methods}

A. The material chosen for this experiment consisted of a breeding population viz. the $\mathrm{F}_{6}$-generation of $M$. sativa originating from consecutive generations of " phenotypic-truncation-selection " followed (in each generation) by random mating of the selected parents (Daday, 1962); this material still contained considerable genetic variance of growth characters. Up to 18 full-sib families of that $F_{6}$ were sown in boxes then transplanted into four naturally diverse geographical locations; namely at Canberra, A.C.T., two sites (1) Charnwood and (2) Glebe (differing in soil type) and (3) at Yanco and (4) at Narrabri, N.S.W.

Field plantings were made between June and September 1965 in rows 40 inches apart, with 28 inch spacings within the rows, and consisting of a total of approximately 3600 plants in four replications (" within" families) at each of the above-listed experiment areas.

The planting of unequal numbers of families at the localities has been and is due to husbandry- and administrative-difficulties.

B. The metric properties analysed were:

(a) Growth-ranking. Yield capacity of the spaced plants was subjectively ranked within generations one to six throughout the whole experiment. The scores were made in December or January (long day, high temperature) and in July (short day, low temperature).

(b) Plant height was measured in inches (not in all successive generations). Plant productivity can usually be correlated with plant height but in the case of a plant with "creeping " conformation (such as the present strains of $M$. sativa), it's population values are usually effected also by plant diameter; hence this height measurement was not included in the detailed analysis, except as indicating the general mean growth performance, or to confirm the estimates of genetic variance of growth-ranking under low treatment in the same population.

C. At each locality the population was exposed successively to several 
(two, in some; three, in other sites) different treatments: these treatments have been designated:

(i) High, when the measurements of growth were made during the long day and high temperature conditions of summer of 1965-66 with the plots receiving adequate moisture by irrigation.

(ii) Medium, when measurements were made during the short days and low temperature of the winter of 1966, again under irrigation to supply sufficient moisture.

(iii) Low, when the families were grown under high temperatures and long days but without irrigation in the 1966 summer. Stress conditions (soil-moisture-deficiency) resulted from natural drought. Rainfall was nil and only limited residual soil moisture was available to the plants between the previous harvest and the time of the data collection at Gharnwood and Yanco.

The mean daily temperatures and daylengths at Canberra, Yanco and Narrabri are as follows:

\begin{tabular}{|c|c|c|c|c|c|c|}
\hline & & & Local & ities & & \\
\hline & Canb & erra & Yanco & Leeton) & Narra & abri \\
\hline & $\begin{array}{l}\text { Mean temp. } \\
\quad\left({ }^{\circ} \mathrm{F} .\right)\end{array}$ & $\begin{array}{c}\text { Daylength } \\
\text { (hours) }\end{array}$ & $\begin{array}{l}\text { Mean temp. } \\
\quad\left({ }^{\circ} \mathrm{F} .\right)\end{array}$ & $\begin{array}{c}\text { Daylength } \\
\text { (hours) }\end{array}$ & $\begin{array}{l}\text { Mean temp. } \\
\quad\left({ }^{\circ} \mathrm{F} .\right)\end{array}$ & $\begin{array}{c}\text { Daylength } \\
\text { (hours) }\end{array}$ \\
\hline January & $69 \cdot 3$ & 14.27 & 76.0 & $14 \cdot 19$ & $80 \cdot 4$ & 13.86 \\
\hline July & $42 \cdot 8$ & 10.00 & 47.8 & 10.06 & $51 \cdot 0$ & $10 \cdot 38$ \\
\hline
\end{tabular}

D. Calculation of heritability based on between $\left(\hat{h}_{F}^{2}\right)$, within $\left(\hat{h}_{W}^{2}\right)$ (single plot) family means, and on extrapolated $h_{n}^{*}$ (" narrow heritability").

\section{(a) Family and within plot heritability}

The expected mean squares and calculation of heritabilities are as follows :

\begin{tabular}{|c|c|c|c|}
\hline Families & $\begin{array}{l}\text { M.S. } \\
\text { F }\end{array}$ & $\begin{array}{c}\text { Exp. M.Sq. } \\
\sigma_{E}^{2}+r \sigma_{F}^{2}\end{array}$ & $\begin{array}{l}\text { Exp. M. Product } \\
\operatorname{cov}_{E}+r \operatorname{cov}_{F}\end{array}$ \\
\hline Replications & $\mathrm{R}$ & & \\
\hline Fam. $\times$ Rep. & $\mathrm{E}$ & $\sigma_{E}^{2}$ & $\operatorname{cov}_{E}$ \\
\hline
\end{tabular}

Where $r$ is the number of replications involved, $\sigma_{F}^{2}$ is the component of variance between families, and $\sigma_{E}^{2}$ is the family $\times$ replication interaction mean square. These components have been estimated as

$$
\hat{\sigma}_{F}^{2} \simeq \frac{1}{r}(\mathrm{~F}-\mathrm{E}) ; \quad \hat{\sigma}_{E}^{2} \simeq \mathrm{E},
$$

family and plot heritabilities as

$$
\hat{h}_{F}^{2}=\frac{\hat{\sigma}_{F}^{2}}{\hat{\sigma}_{F}^{2}+\frac{\hat{\sigma}_{E}^{2}}{r}} ; \quad h_{W}^{2}=\frac{\hat{\sigma}_{F}^{2}}{\hat{\sigma}_{F}^{2}+\hat{\sigma}_{E}^{2}}
$$

respectively. 


\section{(b) Approximation to $\hat{h}_{n}^{2}$-estimates by extrapolation}

As no family structure was available for the $\mathrm{F}_{6}$ generations, direct estimation of $\hat{h}_{n}^{2}$ (narrow heritability) values for that generation was impossible, therefore they were obtained by extrapolation from information on $\mathrm{F}_{3}, \mathrm{~F}_{4}$ at Canberra (Charnwood) for high and medium growth score, height measurement (for which family structures are available).

An analysis was carried out and estimates of sire, dam, sire $\times$ dam, etc. components were obtained. Two sets of $\hat{h}_{n}^{2}$ 's were obtained for the $\mathrm{F}_{3}$ and $\mathrm{F}_{4}$ for both medium and high, which are as follows:

(i) using an average of sire and dam components as genetic component; and

(ii) using the sire component only.

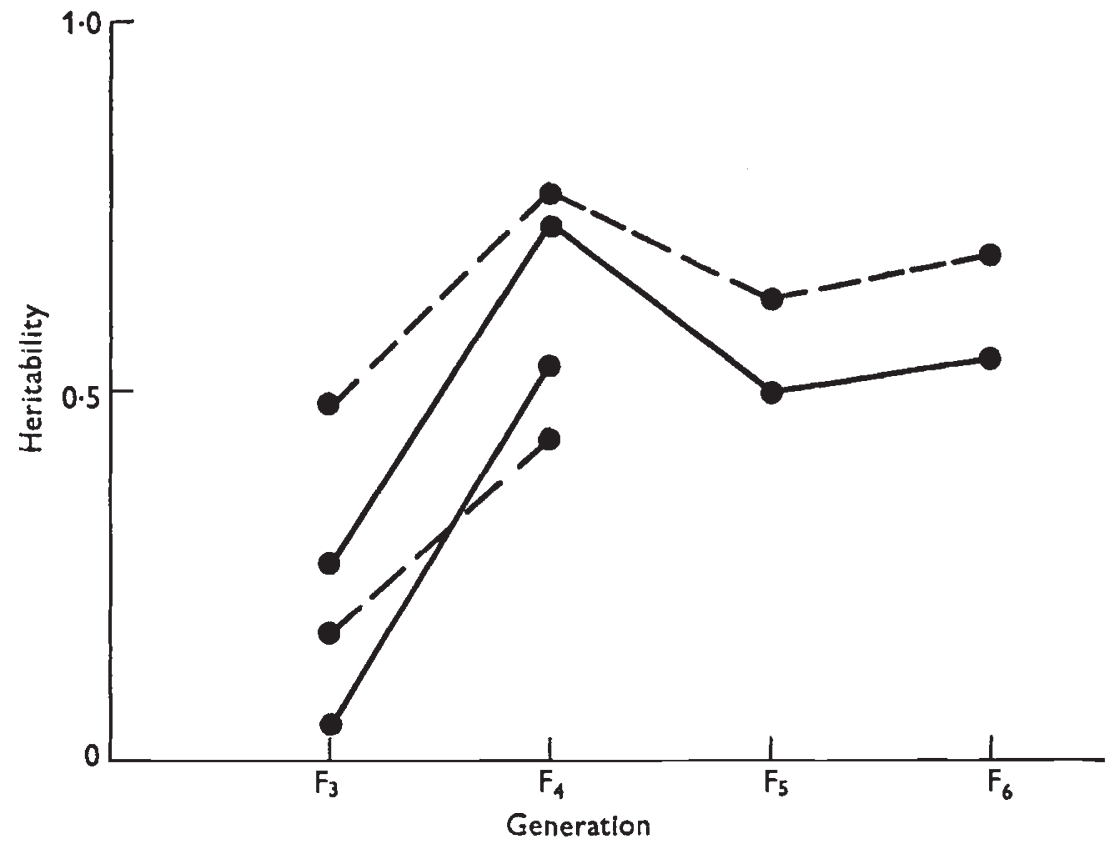

Fic. 1.-High (-), and medium (-- $) \hat{h}_{n}^{2}$ from sire components in $\mathrm{F}_{3}, \mathrm{~F}_{4}$ and $\hat{h}_{W}^{2}$ in four generations for Canberra (Charnwood).

The $\hat{h}_{n}^{2}$ 's from (i) were close to the respective $\hat{h}_{w}^{2}$ 's (possibly because both contained a component due to the same "maternal effect"). The $\hat{h}_{n}^{2}$ 's from sire component only were lower; however, the lines joining $\hat{h}_{n}^{2}$ and $\hat{h}_{W}^{2}$ relevant to $\mathrm{F}_{3}, \mathrm{~F}_{4}$ appeared to be parallel for both high and medium (fig. 1). Besides it appeared that a plateau could have been reached at the $F_{4}$ for the $\hat{h}_{W}^{2}$. Assuming that the parallelism between $\hat{h}_{n}^{2}$ 's and $\hat{h}_{W}^{2}$ 's extends beyond the $\mathrm{F}_{4}$ generation, then a plateau would have been expected to have been attained by the $h_{n}^{2}$. This would then justify an extrapolation of the $\hat{h}_{n}^{2}$ 's from the $F_{3}, F_{4}$ for Canberra (Charnwood) to the $F_{6}$ for all areas using the formula defining " $h_{n}^{2}$ " as follows:

$$
\hat{h}_{n F_{6}}^{*}=\frac{\hat{h}_{n F_{4}}^{2}(\mathrm{C})}{\hat{h}_{W F_{4}}^{2}(\mathrm{C})} \cdot \hat{h}_{W F_{6}}^{2}
$$


for high and medium, where $\mathrm{C}$ in brackets stands for Canberra (Charnwood).

The extrapolation yielded $\hat{h}_{n}^{2}, F_{B}$ are entered in the bottom row of table 3. The $\hat{h}_{W}^{2}$ 's for low are too close to zero to permit their uses in such tentative supplementation to estimation.

The correlation coefficients were estimated following Falconer (1960). The predicted direct response to selection was calculated as

$$
R_{n}=i \hat{\sigma}_{F} \hat{h}_{n}^{*}
$$

where $R_{n}$ is the estimated expected response; $i$ is the selection differential, which was kept constant; $\hat{\sigma}_{F}$ the family phenotypic standard deviation and $\hat{h}_{n}^{*}$ is the above described extrapolated estimate of narrow heritability. The estimate of the (desirable, although concomitant) response of a population in a "secondary" environment to (actually merely "indirect") selection of families in the "primary" environment is expressed (being a "correlated response") as

$$
C R_{y}=i_{x} \hat{h}_{x} \hat{h}_{y} r_{A_{x y}} \sigma_{P_{y}}
$$

where $i_{x}$ is the selection differential, $\hat{h}_{x}$ and $\hat{h}_{y}$ are the square roots of the heritabilities of the character in terms of $x$ in the primary and secondary environments, $r_{A_{x, y}}$ is the genetic correlation between the equivalent characters in the two environments and $\sigma_{P_{y}}$ is the phenotypic standard deviation of the character in the secondary environment.

\section{RESULTS}

\section{(a) Effect of the environment on the mean values and on the heritabilities}

The relative mean growth measurements of the moieties of the experimental population of $M$. sativa were significantly affected by the three environmental treatments at Canberra. When lower temperature and shorter daylength were the characteristics of the contrasts between high and the medium levels, mean plant height decreased from $26.5 \pm 0.22$ to $9.0 \pm 0.05$ inches. With the addition of "moisture stress" to "long days" and " high temperature", plant height was further restricted to a mean of $3.0 \pm 0.02$ inches.

The effects of high, medium and low treatments on the variances of mean plant growth rankings of moieties at each of the four sites (table l) show significant differences between families in all of the high and medium treatments, but the low treatment reduced the between families' variance-estimates below the pre-assigned level of significance both at Canberra and Yanco. Plant height measurements (inches) at low treatments showed no ascertainable genetic variation: this confirms the findings on plant growth-scoresobservations.

As the experimental population appeared to be highly sensitive to the varying environments, an analysis was made to ascertain whether the relative ranking in mean response would be similar between localities within high, medium and low treatments (table 2).

For both high and medium treatments the family $\times$ location interaction estimates are significantly higher than the within location-within family 
variance estimates. However, for low treatment, the estimated samplingvariance actually exceeds the interaction mean square, but of course not significantly so.

TABLE 1

Analyses of variances of mean plant growth of families at high, medium and low treatments within four localities in $M$. sativa

(a) Rankings

High treatment

\begin{tabular}{|c|c|c|c|c|c|c|c|c|}
\hline \multirow[b]{2}{*}{ Variances } & \multicolumn{2}{|c|}{ Canberra-Charnwood } & \multicolumn{2}{|c|}{ Canberra-Glebe } & \multicolumn{2}{|c|}{ Yanco } & \multicolumn{2}{|c|}{ Narrabri } \\
\hline & d.f. & M.S. & d.f. & M.S. & d.f. & M.S. & d.f. & M.S. \\
\hline $\begin{array}{l}\text { Families } \\
\text { Replications } \\
\text { Residual }\end{array}$ & $\begin{array}{r}17 \\
3 \\
51\end{array}$ & $\begin{array}{l}0.227 * * * \\
0.357 * * * \\
0 \cdot 038\end{array}$ & $\begin{array}{r}16 \\
3 \\
48\end{array}$ & $\begin{array}{l}0 \cdot 106^{* *} \\
0 \cdot 412^{* * *} \\
0 \cdot 038\end{array}$ & $\begin{array}{r}16 \\
3 \\
48\end{array}$ & $\begin{array}{l}0 \cdot 247 * * \\
0 \cdot 176 \\
0.089\end{array}$ & $\begin{array}{r}10 \\
3 \\
30\end{array}$ & $\begin{array}{l}0 \cdot 226^{*} \\
0 \cdot 147 \\
0 \cdot 102\end{array}$ \\
\hline \multicolumn{9}{|c|}{ Medium treatment } \\
\hline $\begin{array}{l}\text { Families } \\
\text { Replications } \\
\text { Residual }\end{array}$ & $\begin{array}{r}17 \\
3 \\
51\end{array}$ & $\begin{array}{l}0 \cdot 387 * * * \\
0 \cdot 197 * * \\
0 \cdot 038\end{array}$ & $\begin{array}{r}16 \\
3 \\
48\end{array}$ & $\begin{array}{l}0 \cdot 602^{* * * *} \\
0 \cdot 704^{* * * *} \\
0.054\end{array}$ & $\begin{array}{r}16 \\
3 \\
48\end{array}$ & $\begin{array}{l}0.790 * * * \\
0.382 * * * \\
0.036\end{array}$ & $\begin{array}{r}10 \\
3 \\
30\end{array}$ & $\begin{array}{l}0.381 * * * \\
0.320 * * \\
0.079\end{array}$ \\
\hline
\end{tabular}

Low treatment

\begin{tabular}{|c|c|c|c|c|c|c|}
\hline \multirow[b]{2}{*}{ Variances } & \multicolumn{2}{|c|}{ Canberra-Charnwood } & \multicolumn{2}{|c|}{ Yanco (Jan.) } & \multicolumn{2}{|c|}{ Yanco (Feb.) } \\
\hline & d.f. & M.S. & d.f. & M.S. & d.f. & M.S. \\
\hline $\begin{array}{l}\text { Families } \\
\text { Replications } \\
\text { Residual }\end{array}$ & $\begin{array}{r}16 \\
3 \\
48\end{array}$ & $\begin{array}{l}0.03 \\
0.22 * * * \\
0.03\end{array}$ & $\begin{array}{r}16 \\
3 \\
48\end{array}$ & $\begin{array}{l}0.11 \\
0.38^{*} \\
0.10\end{array}$ & $\begin{array}{r}16 \\
3 \\
48\end{array}$ & $\begin{array}{l}0.05 \\
0 \cdot 19^{*} \\
0.06\end{array}$ \\
\hline
\end{tabular}

(b) Heights (inches)

\begin{tabular}{|c|c|c|c|c|}
\hline \multirow[b]{2}{*}{ Variances } & \multicolumn{2}{|c|}{ Canberra-Charnwood } & \multicolumn{2}{|c|}{ Yanco (Feb.) } \\
\hline & d.f. & M.S. & d.f. & M.S \\
\hline Families & 16 & $0 \cdot 15$ & 16 & 0.74 \\
\hline $\begin{array}{l}\text { Replications } \\
\text { Residual }\end{array}$ & $\begin{array}{r}3 \\
48\end{array}$ & $\begin{array}{l}0 \cdot 42 \\
0 \cdot 18\end{array}$ & $\begin{array}{r}3 \\
48\end{array}$ & $\begin{array}{l}0.67 \\
0.92\end{array}$ \\
\hline
\end{tabular}

*** $\mathrm{P} \leqslant 0.001$. ** $\mathrm{P} \leqslant 0.01$. *P $\mathrm{P} \leqslant 0.05$.

TABLE 2

Analyses of variance of ranking of mean plant growth of families at four localities in $M$. sativa

\begin{tabular}{|c|c|c|c|c|c|}
\hline \multirow[b]{2}{*}{ Variances } & \multirow[b]{2}{*}{ d.f. } & \multicolumn{2}{|c|}{ M.S. } & \multirow[b]{2}{*}{ d.f. } & \multirow{2}{*}{$\begin{array}{l}\text { M.S. } \\
\text { Low }\end{array}$} \\
\hline & & High & Medium & & \\
\hline Families & 10 & 0.087 & $0.479 * * *$ & 16 & 0.027 \\
\hline Localities & 3 & $16 \cdot 406 * * *$ & $1 \cdot 469 * * *$ & 1 & $7 \cdot 135 * * *$ \\
\hline Localities $\times$ families & 30 & $0.044 * * *$ & $0.056^{* * *}$ & 16 & 0.009 \\
\hline Within localities and families & $130 \dagger$ & 0.017 & 0.013 & $73 \dagger$ & 0.017 \\
\hline
\end{tabular}

$\dagger$ Approximate estimated equivalent degrees of freedom from within locality heterogeneous mean squares.

*** $\mathrm{P} \leqslant 0.001$.

Over the sites tested the family effect did not reach significance for the high and low treatments, but is highly significant for the medium treatment.

The heritabilities of plant growth rankings and heights at different levels 
of environmental treatment and geographical localities are shown in table 3.

The estimates of heritabilities between family-means, within single plots, and the (extrapolation-yielded) supplementations of estimates of (" narrow".sense) heritabilities were relatively high and varied between localities. The heritabilities of family means under the medium level were 0.79-0.95 which were significantly larger than the high treatment $(0 \cdot 55-0.83)$ at all localities,

TABLE 3

Heritability estimates of growth at high, medium and low levels of treatments at four localities in $M$. sativa

(a) RANKIngs

$\begin{aligned} & \text { Location } \\ & \text { Seasonal } \\ & \text { climate }\end{aligned}$
$h^{2}$ basis Family means
Single plots
$h_{n}^{*}$ Location
$\quad$ Seasonal
$h^{2}$ basis climate
Family means
Single plots
$h_{n}^{*}$
${ }_{n}^{*}$

\begin{tabular}{|c|c|c|c|c|c|}
\hline \multicolumn{6}{|c|}{ Canberra (Charnwood) } \\
\hline \multirow{2}{*}{\multicolumn{2}{|c|}{$\begin{array}{c}\text { High } \\
0.83 \pm 0.06\end{array}$}} & \multicolumn{2}{|c|}{ Medium } & \multicolumn{2}{|r|}{ Low } \\
\hline & & \multicolumn{2}{|c|}{$0.90 \pm 0.04$} & \multicolumn{2}{|c|}{$0.00 \pm 0 \cdot 10$} \\
\hline \multicolumn{2}{|c|}{$\begin{array}{l}0.55 \pm 0.12 \\
0.39 \pm 0.13\end{array}$} & \multicolumn{2}{|c|}{$\begin{array}{l}0.69 \pm 0.10 \\
0.38 \pm 0.13\end{array}$} & \multicolumn{2}{|c|}{$0.00 \pm 0 \cdot 10$} \\
\hline \multicolumn{6}{|c|}{ Yanco } \\
\hline $\begin{array}{c}\text { High } \\
.64 \pm 0.11\end{array}$ & \multicolumn{2}{|c|}{$\begin{array}{c}\text { Medium } \\
0.95 \pm 0.02\end{array}$} & $\begin{array}{l}\text { Low/Jan. } \\
0.08 \pm 0.11\end{array}$ & \multicolumn{2}{|r|}{$\begin{array}{l}\text { Low } / \mathrm{Feb} \\
-0.14 \pm 0.07\end{array}$} \\
\hline $\begin{array}{l}.31 \pm 0.13 \\
.27 \pm 0.13\end{array}$ & \multicolumn{2}{|c|}{$\begin{array}{l}0.84 \pm 0.06 \\
0.46 \pm 0.13\end{array}$} & $0.02 \pm 0 \cdot 10$ & \multicolumn{2}{|r|}{$-0.04 \pm 0.09$} \\
\hline \multicolumn{6}{|c|}{ (b) Plant heights (inches) } \\
\hline & \multirow{2}{*}{\multicolumn{2}{|c|}{$\begin{array}{l}\text { Location } \\
\text { Seasonal } \\
\text { climate }\end{array}$}} & $\begin{array}{l}\text { Canberro } \\
\text { (Charnwoo }\end{array}$ & & Yanco \\
\hline$h^{2}$ basis & & & Low & & Low \\
\hline \multicolumn{3}{|c|}{ Family means } & $-0.21 \pm 0.1$ & & $-0 \cdot 16 \pm 0 \cdot 12$ \\
\hline \multicolumn{3}{|l|}{ Single plots } & $-0.04 \pm 0.1$ & & $-0.05 \pm 0.11$ \\
\hline
\end{tabular}

$\hat{h}_{n}^{2}$ values of high and medium varied between $0 \cdot 16-0 \cdot 46$. Relative to environmental variability the genetic variability under the low treatment régime was considerably reduced, both at Canberra (Charnwood) and Yanco. This is strong evidence in favour of our conjecture that unfavourable natural conditions do, in fact, diminish the expression of genetic variance.

\section{(b) Genetic correlation}

The family $\times$ locality interaction was highly significant within the high and medium levels in the pooled analysis and, hence, a detailed analysis was also carried out to elucidate the relative performance of families at pairs of localities within each treatment. The genetic correlation coefficients between mean plant-growth-scores at different localities are shown in table 4 .

Positive high correlation coefficients $(0.61)$ between families at Narrabri and Yanco, and between the two Canberra experiments of Charnwood and Glebe (0.68), contrast with the low Narrabri-Canberra correlation for the high treatment. A similar correlation coefficient pattern was found in the medium treatment, except that the correlations between Yanco and the two Canberra sites were highly positive $(0 \cdot 82)$. No correlation was found between Yanco and Canberra for the low treatment. 
Further analyses (table 5) examined the correlation of growth rankings between high and medium and between high and low treatments resulting in not significant or zero correlations.

TABLE 4

Estimated genetic correlation coefficients between the "mean growth scores" (within high, medium and low levels of treatments) at different localities

\begin{tabular}{|c|c|c|c|c|c|c|}
\hline \multirow[b]{2}{*}{ Locality } & \multicolumn{3}{|c|}{ High } & \multicolumn{3}{|c|}{ Medium } \\
\hline & Yanco & $\begin{array}{c}\text { Canberra } \\
\text { (Charnwood) }\end{array}$ & $\begin{array}{c}\text { Canberra } \\
\text { (Glebe) }\end{array}$ & Yanco & $\begin{array}{c}\text { Canberra } \\
\text { (Charnwood) }\end{array}$ & $\begin{array}{c}\text { Canberra } \\
\text { (Glebe) }\end{array}$ \\
\hline $\begin{array}{l}\text { Narrabri } \\
\text { Yanco } \\
\text { Canberra } \\
\text { (Charnwood) }\end{array}$ & $0.61 *$ & $\begin{array}{r}-0.19 \\
-0.17\end{array}$ & $\begin{array}{l}0.07 \\
0.36\end{array}$ & $0.68 * *$ & $\begin{array}{l}0.36 \\
0.82 * *\end{array}$ & $\begin{array}{l}0.36 \\
0.82 * *\end{array}$ \\
\hline
\end{tabular}

$$
\begin{aligned}
& \text { Locality } \overbrace{\text { Yanco (Jan.) }}^{\text {Low }} \text { Yanco (Feb.) } \\
& \text { Canberra } \\
& \begin{array}{lll}
\text { (Charnwood) } \quad 0.0 & 0.0
\end{array} \\
& * \equiv(0.01 \leqslant P<0.05) . * * \equiv(0.001 \leqslant P<0.01) . * * * \equiv(P \leqslant 0.001) .
\end{aligned}
$$

Unfavourable environmental conditions depressed the heritabilities with respect to all metric characters investigated (of course, the mean growth values of the populations are diminished by the same condition). These can result from a general effect on all physiological properties other than growth or from the selective partial elimination of some genotypes under

TABle 5

Genetic correlation coefficients between the mean plant growth scores among the three treatment levels at different localities

\begin{tabular}{|c|c|c|}
\hline Yanc & $\begin{array}{c}\text { Canberra } \\
\text { (Charnwood) }\end{array}$ & $\begin{array}{c}\text { Canberra } \\
\text { (Glebe) }\end{array}$ \\
\hline
\end{tabular}

High

$$
\text { Locality }
$$
(medium)

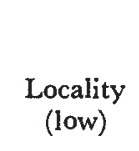

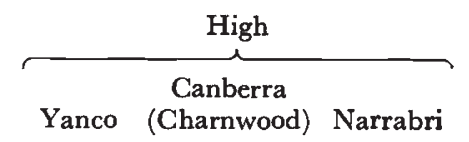

Narrabri

0.23

$$
-0 \cdot 13
$$$$
-0.07
$$

Canberra

$$
-0.42
$$$$
\begin{array}{ll}
0.26 & -0.42 \\
0.14 & -0.35
\end{array}
$$$$
\begin{array}{r}
-0.09 \\
-0.10
\end{array}
$$
(Charnwood)
Yanco (Jan.)

Yanco (Feb.)

$-0 \cdot 10$

0.00

$$
0.00
$$

Yanco

(Charnwood)

unfavourable conditions. Mortality of plants between the times of the last scoring under favourable conditions and the scoring under low conditions was not greater than 5 per cent. The analysis of the percentage of dead plants in families occurring within high and low observations was not significant (V.R. $=1.23$; when V.R. $=1.96$ for $n_{1}=17, n_{2}=51, \mathrm{P}=0.05$ at Canberra and V.R. = 1.86; when V.R. $=2.01$ for $n_{1}=16, n_{2}=48$, $P=0.05$ at Yanco), indicating that the mortality of plants was not affecting specific families. Observations of plant growth scores were made when 10 per cent. of the populations were flowering both in the high and low treatments. These results suggest that neither the expression of flowering time nor selective mortality contributed to the reduction of heritability. 
(c) Nature of the predicted selection response

Estimates of the expected response to direct and indirect selection, calculated from the available estimates of heritability $\left(\hat{h}_{n}^{2}\right)$, phenotypic standard deviation and genetic correlation of growth ranking, are shown in figs, 2 to 5 .

Fig. 2 shows the expected relative responses to direct selection of families under high and low treatments at four localities during six generations, assuming that $\hat{h}_{n}^{2}$ and $\sigma_{P}$ remain constant. There will be substantial response to

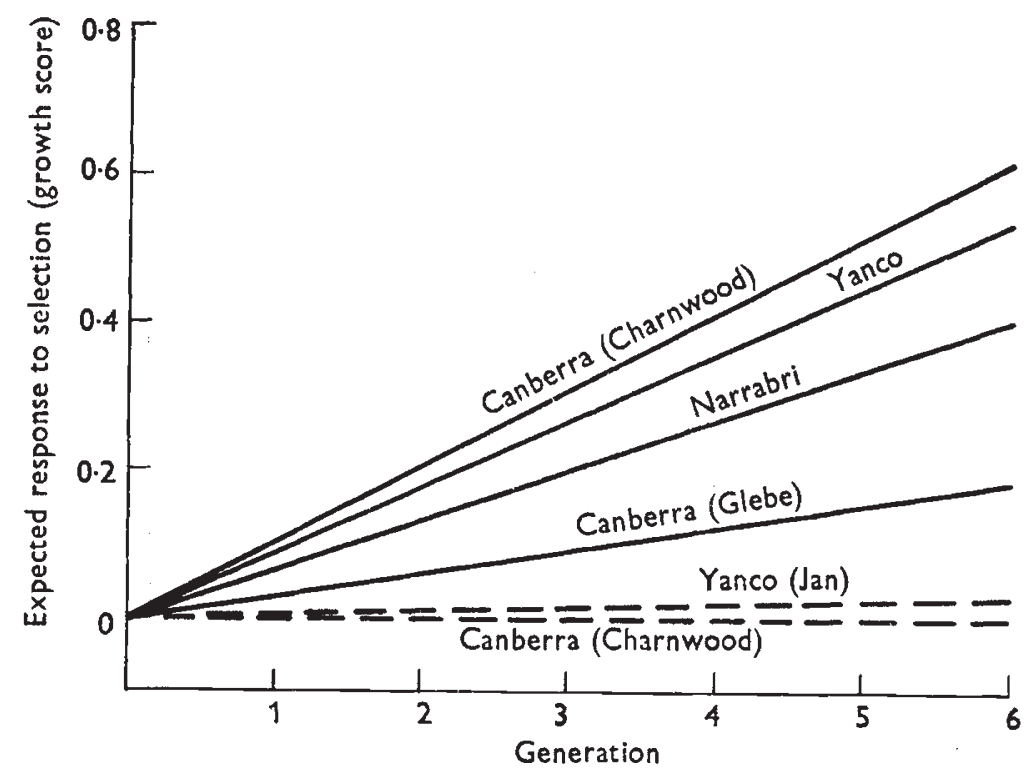

FIG. 2.-Expected response to direct selection during six generations under favourable (high: -) and unfavourable (low: - -) environmental conditions at four localities.

selection under the high level treatment at Canberra, whereas the low treatment will eliminate all response at Canberra and give low responses at Yanco. Within high treatments there are no significant differences between predictions (based on heritability-estimates) of selection-responses.

The expected relative responses under medium conditions substantially exceeded the predicted relative responses under high treatment (fig. 3).

Fig. 4 summarises responses (throughout six consecutive generations) to indirect selection in high environments. In the inscriptions (relating to the response-curves) an arrow points from the name of the locality of selection to that of the one of performance.

The highest predicted response to indirect selection is obtained for selection practised at one Canberra locality (Glebe) for performance in the second Canberra locality (Charnwood). If indirect selection is carried out at Narrabri for Yanco, a sufficient response to selection can be expected, although this will still be only 48 per cent. of the direct selection response at Yanco, but any selection at Canberra (Charnwood) would result in reduced performance at Narrabri and Yanco. In medium environments, however, no negative responses are predictable to any indirect selection-procedures: e.g. to the very example of negative response-prediction (viz. selecting at 


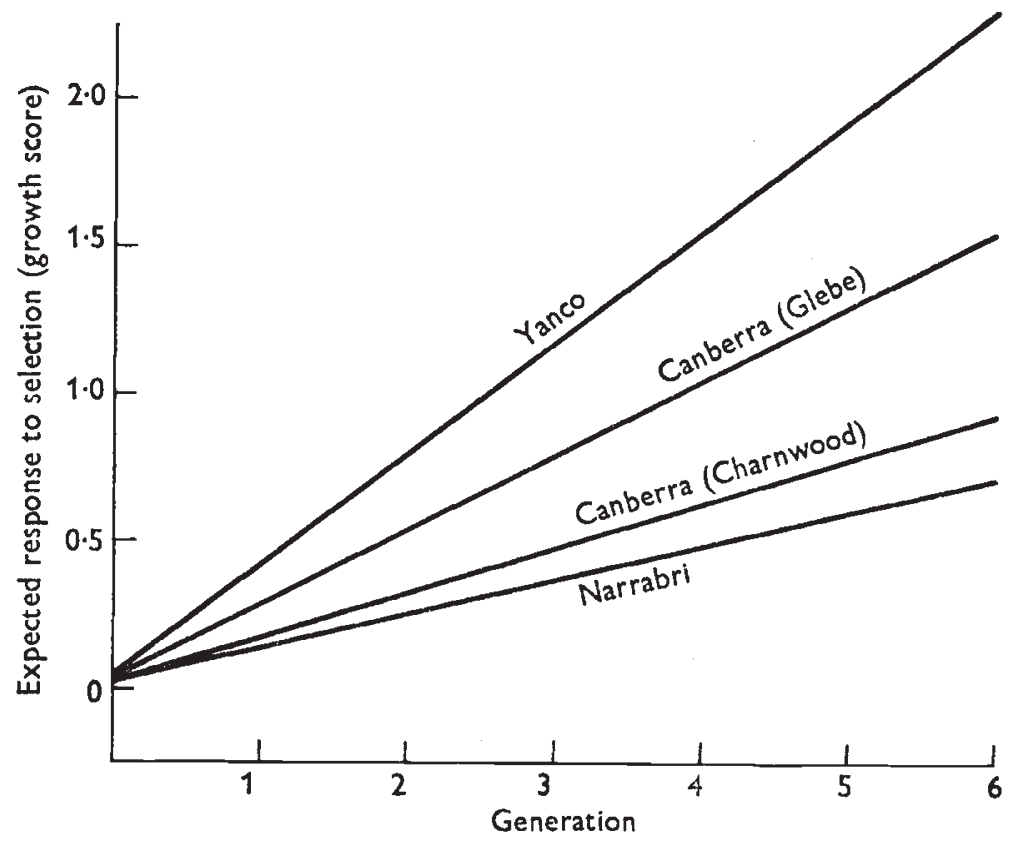

Fig. 3.-Expected response to direct selection during six generations under medium environmental conditions at four localities.

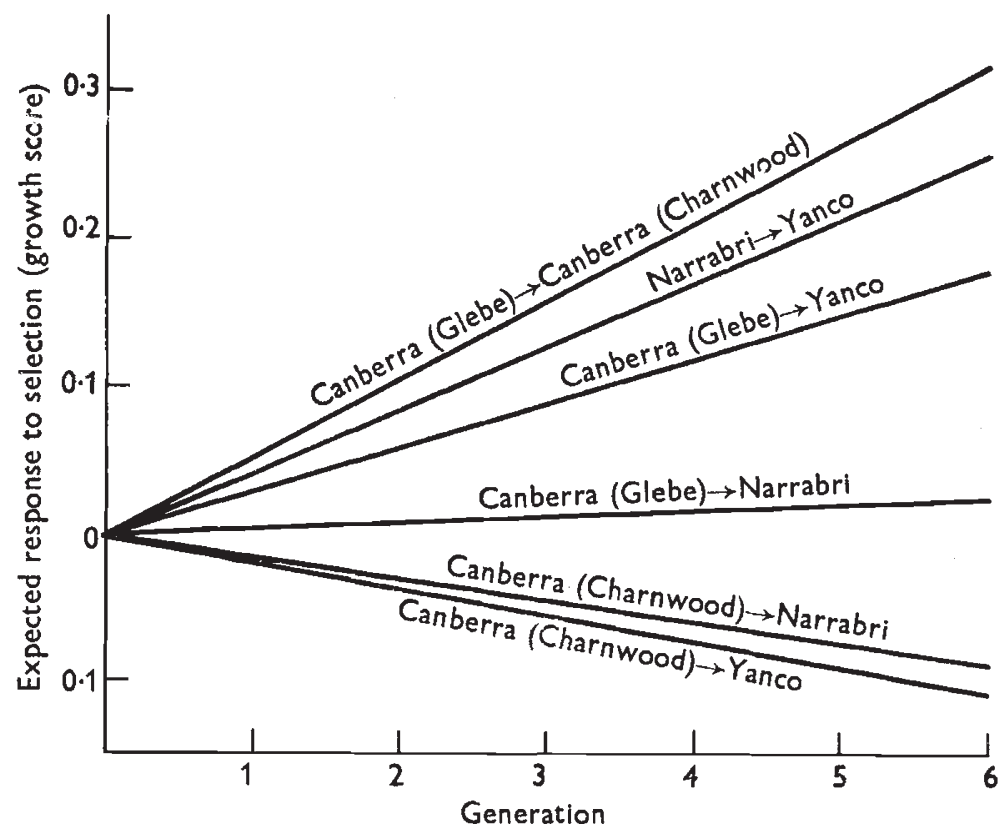

Frg. 4.-Expected response to indirect selection during six generations under favourable (high) environmental conditions at one locality for another as indicated by an arrow. 
Charnwood, for performance at Yanco) an exceedingly positive one corresponds! Moreover, the overall pattern over all localities of relative responses shows a marked superiority of medium compared with high environments (fig. 5).

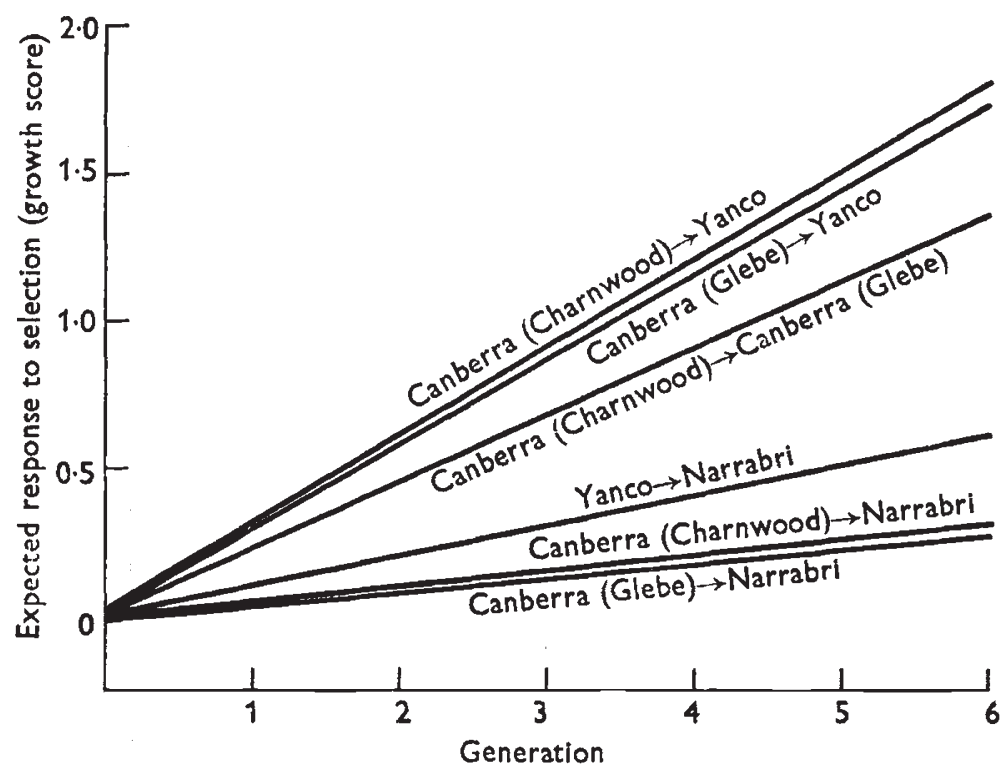

FIG. 5.-Expected response to indirect selection during six generations under medium environmental conditions at one locality for another as indicated by an arrow.

Although direct selection was found in this context to be superior to all indirect systems, the occurrence of frequent unfavourable environmental conditions (moisture stress) with an associated low heritability expression would have a severely retarding effect even on direct selection.

The direct selection response under the high treatment at Yanco, when affected by an increasing number of generations grown in unfavourable environmental conditions, is indicated by the gradually increasing low response line in fig. 6.

The maximum response to selection can be expected if the population is selected through six generation cycles under favourable conditions, but if three or more generations have been affected by unfavourable conditions, indirect selection is predicted to have an advantage, if carried out at Narrabri for Yanco.

\section{Discussion}

The presented experiments demonstrated that "stress conditions" reduced genetic variances of the metric characters investigated and, therefore, the predicted responses to selection are considerably less under stress than under more favourable conditions. Therefore, it is reasonable to predict that when selection is carried out under stress conditions, and the product transferred to a favourable environment, the achievement will be inferior to that of the product of selection completed in a favourable environment. 
Recalling figs. 3 and 5 we note that in medium environment the predicted relative response both to direct and to indirect selection can be seen to exceed markedly that in high environment (q.v. figs. 2 and 4).

At this stage it appears expedient to recollect a conspicuous feature apparent in table 4: the genetic correlations between performances in different localities appear more important in medium than in high environments;

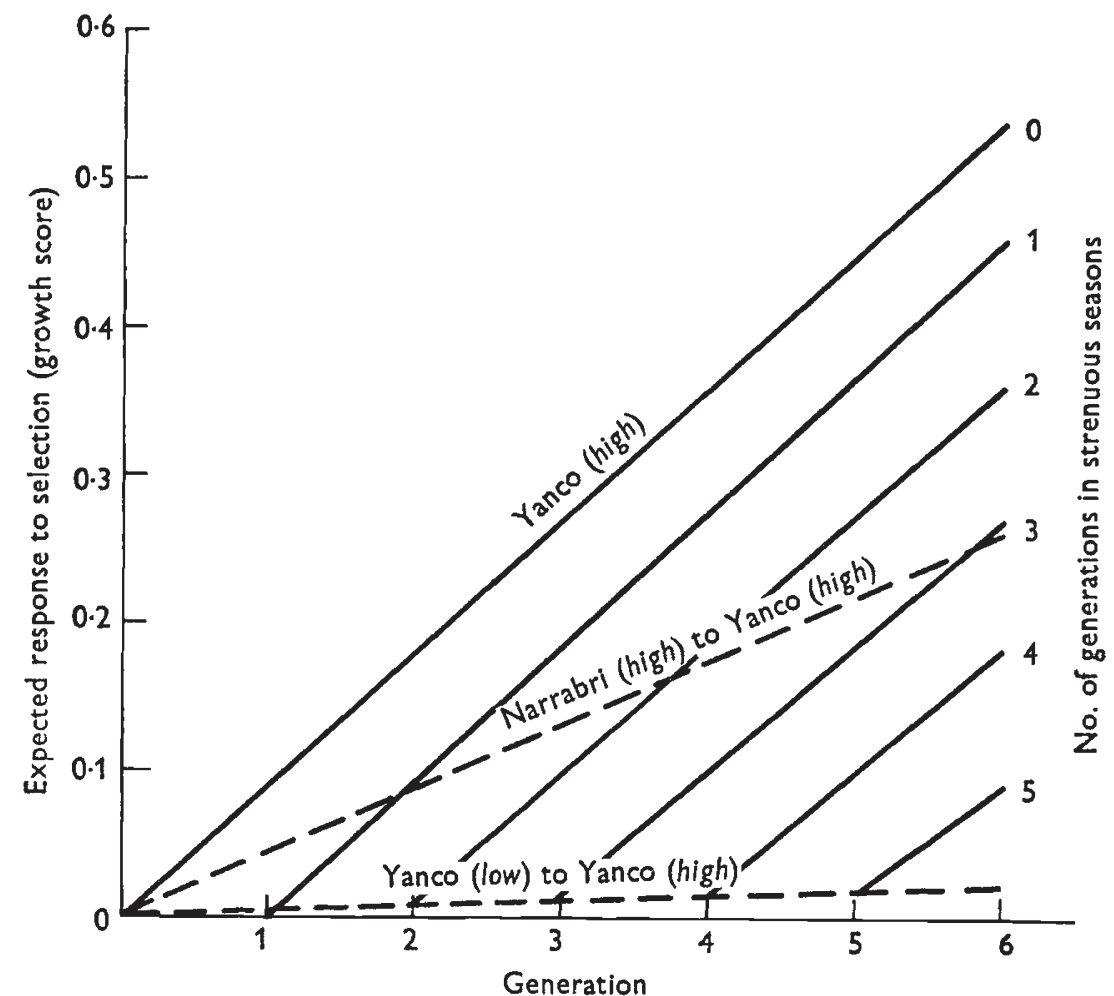

FIG. 6.-Expected response in a high environment to selection during increasing numbers of generations under unfavourable environmental conditions at Yanco $(-)$ under indirect selection at Narrabri high for Yanco high (- - ) and at Yanco low to high (- - - )

in low, these correlations fail to reach observable magnitudes. Although, we are not able to formulate rigorously a model to account for these remarkable phenomena we submit the conjecture that it is a manifestation of the analogous biological substrate as the above-mentioned ranking of predicted selection responses. It is conjectured that the phenotypic expression of favourable genetic resources is more important under moderate stress than under optimum conditions (where individuals of inferior genotypes have reasonable chance to prosper), or under extremely unfavourable conditions where resources are so depleted that even the genetically best equipped individual will fail in supplementing them. In other words medium conditions favour phenotypic expression of genetic resources more than either extremes. Both selection response and genetic correlation are strictly dependent on phenotypic expression of genotypes of individuals, thus on that of genetic resources of the species-moiety under consideration. 
Developmental homeostasis (Lerner, 1954; Dobzhansky and Levene, 1955 ) is a critical contingency, when the stability of the phenotypic expression of genotype in a plant population under environmental variation is of importance. The present investigation relates to a mainly cross-bred (hence, probably, highly homeostatic) population; however, a rather different effect may arise when the homozygous strains are in abundance as well: a situation described and analysed by Griffing and Langridge (1963). Finlay (1963) found variation in general combining ability among a large number of barley varieties grown under various natural environmental conditions in South Australia. His results suggest that different genotypes may find expressions with high or low combining ability in differing environments. However, the barley discussed was grown during winter and spring, while $M$. sativa is a perennial with the ability to grow during summer, when stress conditions are much more likely to occur.

The nature and level of the environmental stress conditions differed in the experiments discussed here from those occurring in Falconer and Latyszewski's (1952). While they exposed the mouse population to low nutrition, reducing the level by 25 per cent., the present experiment had high and medium levels of natural daylight and temperature, with no limitation of soil moisture, and the low treatment was induced by natural moisture stress. Although the reduction of natural daylight and temperature from high to medium caused a significant reduction of mean heights, heritability was increased; however, natural soil moisture stress reduced both mean height and heritability. Morley (1956) tested the findings of Falconer and Latyszewski with Merino sheep under semi-natural conditions and found evidence supporting their conclusions. This evidence suggests the presence of an internal mechanism which made possible some adaptation of these animals to extreme environmental conditions: these physiologically homeostatic self-regulating safeguards of the animals' functionings prevent excessive losses of the substrate of genetic variation.

It may be tentatively conjectured that the significant (but by no means surprisingly large) correlations between performances (e.g. " mean growth scores ") at various localities under high conditions are at least partially due to similarity of environments when the favourable manifestation of the seasonal variation evens out (to some extent) some of the differences between the conditions at the localities considered. Furthermore, under medium "treatment" the corresponding correlations appear surprisingly larger; it is submitted that these (perhaps not significant) increases may be partly due to the manifestation of certain epistatic components whose expression is known to be (e.g. Griffing, personal communication) favoured by moderate stress.

However under low conditions the stress on the population considered may become so excessive as to be beyond compensating even by the most favourable (even by an epistatically strengthened) genotype: consequently the performance becomes so dependent on the availability of (slightly) tolerable " niches" availability in some, but not in other localities: that the phenotypic correlations between performances at various localities, become so attenuated that no significant genetic component can be extracted from them.

Vagueness of definition of " unfavourable environment" explains some of the inconsistency between the results reported by different teams which 
investigated selection-responses under stress-conditions. Therefore, we emphasise that when a population has existed for a considerable number of generations under a particular environment, at some loci allele-frequencyequilibria have been reached. Although the means of populations vary depending on the magnitude of external factors (temperature, daylight, plane of nutrition, etc.), adequate genetic variances can be found in populations, observed at any point of the normal range of conditions; this includes "favourable" environment. If, however, a population is exposed over several generations to an environment where the magnitudes of external factors are markedly outside the normal range, then insufficient variability of allele frequencies is likely to persist, hence the ability to cope eventually with possible new condition is depleted. This is called a " stress condition ": in which not merely the mean, but also the genetic variance of the population is markedly reduced. In extreme cases no significant genetic correlation exists any more between performances of genotypes under favourable and unfavourable conditions.

Different species investigated are likely to be affected in the above outlined pattern (i.e. in danger of some depletion of their genetic reserves), by specific features of their environment: e.g. Griffing and Langridge (1963) demonstrated that high temperature reduces the growth of Arabidopsis thaliana. In the investigation of other species the reduction of heritabilityestimates by stress conditions (moisture stress and low quality of soil) has also been demonstrated for grain yield in oats (Frey, 1964) and in wheat (Gotoh and Osanai, 1959). Frey interpreted his findings by stating that more rapid progress could be expected from selection under " non-stress" conditions.

On the other hand, the investigations here discussed took place in extreme conditions; hence its results include no information above heritability estimates under average rainfall conditions at the localities mentioned. Also, the low condition is unlikely to occur in a continuous series of years, longer than 4-5 years. In spite of these limitations of interpretation, the results are still applicable in plant breeding practice.

The heritabilities found in this experiment are higher than expected, due to the fact that this is a synthetic population originating from relatively recent crossing moieties consisting of widely diverse genotypes; the phenotypic expression of its allele content being still in the course of manifestation.

However when calculating the estimated heritabilities all available information was utilised. Admittedly the heritability-estimates for Narrabri location are likely to be less accurate; we see no reason to suspect any bias arising from the unavoidably unequal precisions. In calculating estimated genetic correlations, data from the six families not represented in Narrabri were ignored.

The observation that the relative selection response is substantially greater in medium than in high environment confirms some of Falconer's expectations; on the other hand, the findings on medium versus low treatments validate the substantial features of Hammond's recommendations.

The contingency that the findings, set out in these expositions, appear to conform more closely to Hammond's than to Falconer's schemes, appears to indicate that in the species we studied the metric characters we investigated are genotypically conditioned by more "yield" and less "vigor" loci; i.e. the larger fraction of the relevant alleles possess more of the "additive" 
than of the "non-additive" components in their expression effect. The distinction between metric characters' genetic conditioning by yield and vigour loci and the relevance of the relative importance of these conditionings to the substance of Falconer's criticism of Hammond's recommendation are seen in Lerner, 1950, 1954, 1958; Lerner and Dempster, 1948; Münzig, 1947.

The foregoing conjecture appears appropriate to all the "main effects", estimated in the analysis of our records; however, the effect of " "between families ' $x$ 'between sites ' - interaction" appears to exceed for medium treatments the corresponding effect both under high and low treatments. With respect to the genetic conditioning of this effect (which-being an expression of response-differential-may well play some role in - natural and/or artificialspeciation) we submit the conjecture that it may be due primarily to the support given by " dominance "-effects at the "vigor "loci, to the " additive". effects at the "yield"-loci (i.e. to the component, denoted by Griffing (personal communication), as "cubic").

The implication of these findings is that, if plant improvement programmes are undertaken to increase yield in environments where the moisture level is highly variable, it may be preferable to proceed with a selection programme under more favourable growth conditions and transfer the product of selection to the less favourable climates, where a series of droughts may prevent the selection progress, but rare favourable years still permit the utilisation of the superior genotypes to indirect selection, provided there is an absence of genotype $\times$ environment interaction. Further, should sporadic stress conditions occur in a normally favourable environment, the selection intensity should be considerably reduced to prevent the elimination of potentially useful genotypes: i.e. those potentially essential for perpetuating the cultivars under stress-conditions.

Acknowledgments.-We are greatly indebted to Mr G. A. McIntyre, CSIRO, Division of Mathematical Statistics, Canberra, for the statistical analyses of some of the data, to Dr B. D. H. Latter for his helpful suggestions in the statistical analysis and to $\mathrm{Mr} \mathrm{T}$. Launders for collection of experimental data at Narrabri. We would like to thank Dr R. N. Oram for suggestions with the manuscript, and $\mathrm{Mr} \mathrm{R}$. F. Baye for his able technical assistance during the course of the experiment.

\section{REFERENGES}

DADAY, H. 1962. Breeding for creeping root in lucerne (Medicago sativa L.). 1. The initial response to selection. Aust. F. agric. Res., 13, 813-820.

DADAY, H. 1964. Genetic relationship between cold hardiness and growth at low temperature in Medicago sativa. Heredity, 19, 173-179.

DOBZHANSKY, T. M., AND LEVENE, H. 1955. Genetics of natural populations. XXIV. Developmental homeostasis in natural populations of Drosophila pseudoobscura. Genetics, $40,797-808$.

FALCONER, D. S. 1952. The problem of environment and selection. Amer. Nat., 86, 293-298.

falconer, D. s. 1960. Introduction to Quantitative Genetics. The Roland Press Co., New York.

FALCONER, D. S., AND LATYSZEWSKI, M. 1952. The environment in relation to selection for size in mice. 7. Genet., $51,67-80$.

FINLAY, K. W. 1963. Adaptation-its measurements and significance in barley breeding. Proc. First Int. Barley Genetics Symp. Wageningen, 351-359.

FREY, K. J. 1964. Adaptation reaction of oat strains selected under stress and non-stress environmental conditions. Crop Sci., 4, 55-58.

GOTOH, K., AND OSANAI, s. 1959. Efficiency of selection for yield under different fertilizer levels in a wheat cross. Jap. F. Breed., 9, 101-106. 
GRIFfing, B., AND LANGRIDGE, J. 1963. Phenotypic stability of growth in the self fertilized species Arabidopsis thaliana. Statistical Genetics and Plant Breeding NAS-NRC., 368-394.

HAMMOND, J. 1947. Animal breeding in relation to nutrition and environmental conditions. Biol. Rev., 22, 195-213.

LERner, I. M. 1950. Population Genetics and Animal Improvement. University Press, Cambridge, p. 342.

LERNER, I. M. 1954. Genetic Homeostasis. Oliver and Boyd, London, p. 134.

LERNer, I. M. 1958. The Genetic Basis of Selection. John Wiley and Son, New York, p. 298. LERNER, I, M., AND DEMPSTER, E, R. 1948. Some aspects of evolutionary theory in the light of recent work on animal breeding. Evolution, 2, 19-22.

MORLEY, F. H. W. 1956. Selection for economic characters in Australian Merino Sheep. VII. Interactions between genotype and plane of nutrition. Aust. 7. agric. Res., 7, 140-146.

MÜNZIG, A. 1947. On the causes of inbreeding degeneration. Arch. Fulius Klaus-Stiftung Vererb. Social-anthrop. Rassenhyg., 20, (Suppl.), 152-163. 